\title{
Danis Ella Stent for the management of a non- variceal lower esophageal bleeding in a post liver transplant recipient- first case report
}

\section{Keywords: danis ella stent, upper gi bleeding, LDLT}

\section{Case summary}

44 years old male, a chronic alcoholic since last 20 years was diagnosed with decompensated chronic liver disease. He had frequent hospital admissions during last year in view ascites, haemetemesis, encephalopathy and hepato-renal syndrome respectively. He was evaluated for living donor liver transplantation after 6 months of abstinence. His MELD at the time of admission was 22 and Child score of 11. After thorough donor work up he underwent LDLT. Right lobe graft without MHV was taken. Graft weight was 665 grams with GRWR of 1.2. Post operative course was complicated by high ascitic fluid drainage; sepsis related acute renal failure. Post operatively on day 5 patient had malena and fall in hemoglobin by $1.5 \mathrm{gm} \%$. He required blood transfusions and in otopes in view of hemodynamic instability.

Antimicrobials were escalated empirically. Upper GI endoscopy revealed diffuse mucosal oozing from the lower end of esophagus along with small isolated gastric varix. Glue injection was done, however patient continued to bleed despite supportive measures. Repeat UGI scopy was done, which showed continued generalized ooze from lower end of esophagus. Therefore endoscopic guided Ella danis SEMS was placed with upper end at $25 \mathrm{~cm}$ from GE junction. The patient was stabilized and moved to the intensive care unit. There was no subsequent evidence of upper GI bleed. Patient however continued to deteriorate due to pulmonary sepsis. He later succumbed and expired on POD 22 (Figure 1) (Figure 2).

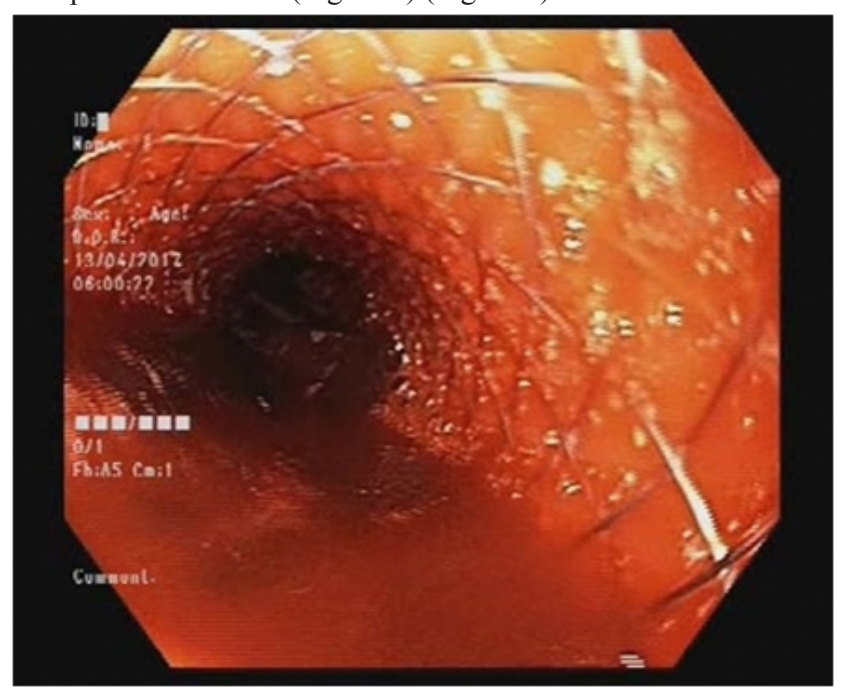

Figure I Endoscopic view of Dannis Ella stent in situ.

\author{
Volume 8 Issue 3 - 2018
}

\author{
Chetan Ramesh Kalal, Akash Shukla, Mihir \\ Vora, Hunaid Hatimi, Amit Maydeo, Ravi \\ Mohanka, Samir Shah \\ Global Institute of Liver Diseases, HPB surgery and \\ Transplantation, India
}

\section{Correspondence: Chetan kalal, Global Institute of Liver} Diseases, HPB surgery and Transplantation, India, Email dr.chetankalal@gmail.com

Received: April 25, 2018 | Published: May 09, 2018

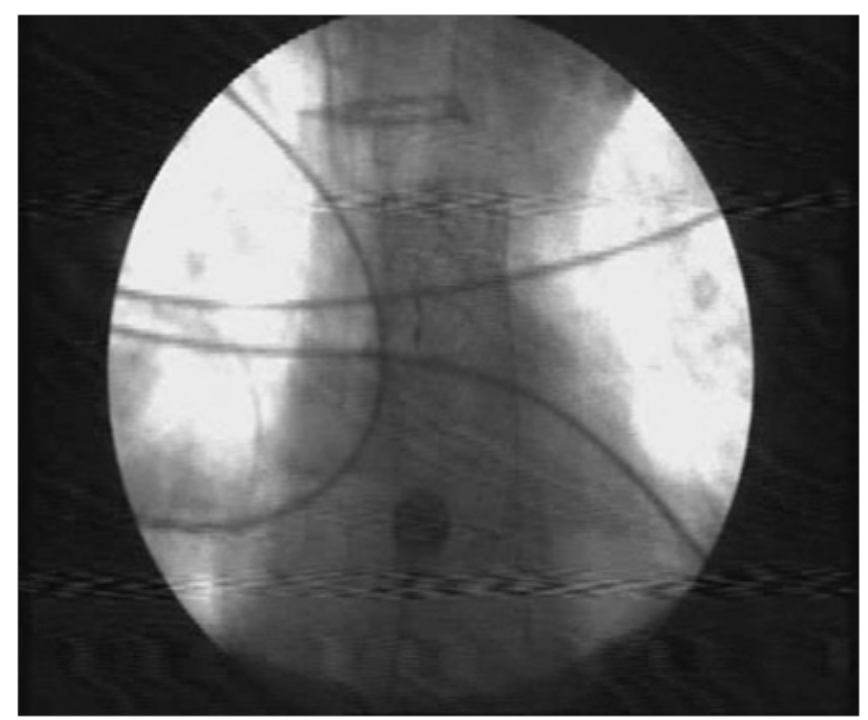

Figure $2 X$ ray view of Dannis Ella stent in situ

\section{Discussion}

To our knowledge, this is the first report of use of Danis Ella stent for non variceal lower esophageal mucosal bleeding in post liver transplant recipient. Our case, showed clinical improvement for some time with regards to control of bleeding and hemodynamic stability post Danis Ella stent placement. Placement of Danis Ella has been shown to effective in achieving hemostasis in patients with refractory esophageal variceal bleeding and post EVL ulcers with low risk of re-bleeding and few untoward events in non transplant patients. This stent can remain in situ for 2 weeks before its removal. ${ }^{1,2}$ There are no published data in current literature on use of Danis ella stent in post transplant setting. In our case, patient succumbed to death, due to sepsis, despite initial improvement in the form of control of bleeding. 
There were no subsequent re-bleeding episodes. Presently, no definite consensus on post-transplant use of Danis ella stent for esophageal bleeding. Our study showed that this stent can be used as bridge to stabilize the patient prior to definitive treatment. Clearly further trials is needed to confirm the safety and efficacy of this approach.

\section{Acknowledgments}

None.

\section{Conflict of interest}

The author declares there is no conflict of interest.

\section{References}

1. Escorsell À, Pavel O, Cárdenas A, et al. Esophageal balloon tamponade versus esophageal stent in controlling acute refractory variceal bleeding: A multicenter randomized, controlled trial. Hepatology. 2016;63(6):1957-67.

2. Dechêne A, El Fouly AH, Bechmann LP, et al. Acute management of refractory variceal bleeding in liver cirrhosis by self-expanding metal stents. Digestion. 2012;85(3):185-91. 